\title{
Substance use disorder and the baby boom generation: Does Berlin outpatient addiction care face a sustained change?
}

\author{
SARA SPECHT ${ }^{1}$ (D), BARBARA BRAUN-MICHL ${ }^{1}$, LARISSA SCHWARZKOPF ${ }^{1,2}$, \\ DANIELA PIONTEK ${ }^{1}$, NICKI-NILS SEITZ ${ }^{1}$, MANFRED WILDNER $^{2,3}$ \& LUDWIG KRAUS ${ }^{1,4,5}$ (1) \\ ${ }^{1}$ IFT Institut für Therapieforschung, Munich, Germany, ${ }^{2}$ Pettenkofer School of Public Health, Ludwig-Maximilians- \\ University, Munich, Germany, ${ }^{3}$ Bavarian Health and Food Safety Authority, Oberschleißheim, Germany, ${ }^{4}$ Department of \\ Public Health Science, Centre for Social Research on Alcohol and Drugs, Stockholm University, Stockholm, Sweden, and \\ ${ }^{5}$ Institute of Psychology, ELTE Eötvös Loránd University, Budapest, Hungary
}

\begin{abstract}
Introduction. The ageing of baby boomers is expected to confront addiction care with new challenges. This cohort had greater exposure to psychoactive substances in youth than earlier cohorts. In this study, we aimed to investigate whether Berlin addiction care is confronted with a sustained change in its clientele initiated by the baby boomers. Methods. Using data from Berlin outpatient addiction care facilities, we contrasted type of primary substance use disorder and number of comorbid substance use disorders in baby boomers with an earlier and a later cohort. To isolate cohort effects, two-level random intercept regression models were applied in the overlapping age groups of the baby boomer cohort with each of the other cohorts. Results. Compared with the earlier cohort, alcohol use disorder lost importance whereas illicit substance use disorder gained importance in the baby boomers. Baby boomers presented a higher number of comorbid substance use disorders than the earlier cohort. Comparing baby boomers with the later cohort, these relationships pointed in the opposite direction. Discussion and Conclusions. Outpatient addiction care faces a sustained change to more illicit and comorbid substance use disorders. With increasing life expectancy and the ageing of baby boomers marked by higher substance use than previous cohorts, older clients, who had been under-represented in outpatient addiction care, will gain relevance. Hence, addiction care has to adapt its offers to appropriately meet the changing needs of its clientele. [Specht S, Braun-Michl B, Schwarzkopf L, Piontek D, Seitz N-N, Wildner M, Kraus L. Substance use disorder and the baby boom generation: Does Berlin outpatient addiction care face a sustained change?. Drug Alcohol Rev 2021;40:979-988]
\end{abstract}

Key words: addiction care, cohort effect, baby boomers, alcohol and illicit substance use disorder, comorbid substance use disorders.

\section{Background}

Baby boomers are the birth cohorts with increased birth rates after World War II. In Germany, the baby boom took place between 1954 and 1969 [1]. Emerging wealth formed them as a generation of selfexpression and pleasure in contrast to previous generations in Western countries [2-4]. Compared with earlier cohorts, baby boomers had greater exposure to alcohol, tobacco and illicit substances in youth [5], developed a higher acceptance towards drug consumption [6] and, as a result, are more susceptible to substance use [5]. Overall, these historical conditions have the potential to influence members of a cohort, which could then play a part in social changing processes $[7,8]$.

With the presence of baby boomers in addiction care, the primary problem for which individuals seek care is expected to shift; compared with earlier cohorts, a decline in the relative relevance of alcohol use disorder (AUD) and an increase in the importance of illicit substance use disorder (ISUD) is anticipated [5,9-12]. Individuals seeking help in addiction care primary for alcohol problems differ substantially

Sara Specht, MPH, Research Assistant, Working Group Therapy and Health Care Research, Barbara Braun-Michl, Dr, Head, Working Group Therapy and Health Care Research, Larissa Schwarzkopf, Dr, Head, Working Group Therapy and Health Care Research, Daniela Piontek Dr, Former Head, Working Group Epidemiology and Diagnostics, Nicki-Nils Seitz, Dr, Head, Working Group Epidemiology and Diagnostics, Manfred Wildner, Dr Prof, Head, State Institute for Health, Bavarian Health and Food Safety Authority, Ludwig Kraus Dr Prof, Director. Correspondence to: Mrs Sara Specht, IFT Institut für Therapieforschung, Leopoldstraße 175, 80804 Munich, Germany. Tel: +49 89360804 47; E-mail: specht@ift.de

Received 15 June 2020; accepted for publication 13 December 2020. 
from those with primary problems related to the use of illicit substances [13] and, subsequently, mark different fields of care.

The suggested upheaval in primary AUD to ISUD diagnoses in baby boomers may be different for women than for men. Despite an ongoing convergence of well-established sex-specific roles [14], sex-specific socialisation processes could lead to temporally shifted cohort effects.

Regarding developments in mental health, there is evidence that later cohorts are burdened with a combination of multiple substance use disorders more often than earlier cohorts $[11,15]$. Based on this, baby boomers are expected to qualify for more comorbid substance use disorders (CUD) than earlier cohorts, which in turn is linked to a higher overall burden and complicates treatment [16-18].

The majority of studies on baby boomer-specific characteristics in addiction come from the USA where legislation, economic and cultural developments may differ, and the baby boom commenced earlier than in Germany [3]. However, similar trends can be expected in all high-income countries because baby boomers were exposed to a similar youth culture that differed from that of their antecedents [4].

As the baby boomer cohort started to reach age 55 years and above from 2010 in Germany, the share of older age groups-which have been underrepresented in addiction care so far-is anticipated to rise as projected in other countries [19-21]. Considering the size, the relatively high life expectancy and the specific substance-related use patterns of this cohort, the baby boomers are an important target group in addiction care, especially when it comes to the older age group. Hence, to facilitate addiction care planning, knowledge about baby boomers and the developments they will set off in the addiction care system is required. In this regard, comparing baby boomers against both an earlier and a later cohort will contribute to a better understanding whether baby boomers mark the beginning of a continuous change of substance-specific help-seeking in outpatient addiction care.

To close the knowledge gap on whether there had been a shift in cohort characteristics in German outpatient addiction care this study aims to examine: (i) whether outpatient addiction care seekers from the baby boomer cohort are less likely to be diagnosed with primary AUD and (ii) more likely to be diagnosed with ISUD than an earlier cohort; (iii) whether cohort effects in the likelihood of being diagnosed with AUD or ISUD differ by sex; (iv) whether baby boomers have more CUDs than an earlier cohort; and (v) whether characteristics observed in the baby boomers continue in a later cohort.

\section{Methods}

\section{Setting and design}

We analysed data from the outpatient Berlin Addiction Care Statistical Service, which contains a case-based documentation of services in facilities of the type 'outpatient counselling and treatment' of the German-wide standardised core dataset [22]. About $88 \%$ of the service provided in the facilities included in the dataset was outpatient addiction counselling and approximately $4 \%$ outpatient detoxification. Hereafter, the term 'outpatient addiction care' is used for these facilities. In case of several individual help-seeking episodes, only the first episode was included. Data were entered by addiction care personnel. The documentation served as a guideline for addressing all relevant issues and contained admission and cessation variables. For comparability reasons, annual data for the years 2008-2016, where an identical set of variables was collected, were used. The annual participation rate ranged from $73 \%$ to $84 \%$ of all registered Berlin outpatient counselling and treatment facilities in the years 2012-2016 (participation rates before 2012 are not available). Data collection was performed in accordance with the ethical standards of the Helsinki Declaration as revised in 2013 and in accordance with regional (Berlin data protection law), national (German data protection law) and international (European General Data Protection Regulation) data protection requirements. Informed consent was obtained from all patients by the data collection facilities. Participation was not linked to any benefits or the selection of treatment offers.

\section{Variables of interest}

Primary and further substance-related diagnoses were coded according to the International Statistical Classification of Diseases and Related Health Problems, 10th revision, German Modification and refer to the 12 months before admission (mostly dependence but also harmful use). Information on diagnoses came from either prior diagnostics, assessment by addiction care personnel with expertise to make diagnoses or a clinician. The primary diagnosis was the addiction-related diagnosis an individual sought help for. ISUD comprised disorders related to the use of opioids, cannabis, cocaine, stimulants, hallucinogens, volatile solvents or other psychotropic substances. CUDs burden reflected a sum score of positive diagnoses on F10-F19 (mental and behavioural disorders due to psychoactive substance use) and F55.0-F55.2 (abuse of the non-dependence-producing substances antidepressants, laxatives and analgesics). F55.0-F55.2 diagnoses were included 
to cover both dimensions of substance-related problems (substance use disorder and abuse of particular medicaments). Cohort membership was defined by year of birth and comprised the following categories: 'baby boomers' born between 1954 and 1969 (annual birth rates above 1.1 million), the 'earlier cohort' born between 1938 and 1953, the 'later cohort' born between 1970 and 1985 .

Age at admission was measured in years. Relationship with a partner was dichotomised into having a stable relationship or not. The level of school education was assessed by means of German degrees. A 'low' school education corresponds to a lower secondary school certificate or less (school attendance $\leq 9$ years) and 'at least middle' school education to an upper secondary school certificate or higher ( $\geq 10$ years of school education). The number of contacts during treatment was documented as well as whether someone had ever used any kind of addiction care service before.

\section{Analyses}

Due to concerns regarding multicollinearity of age and cohort, age at admission was not handled as a control variable [for a discussion, see Ref. 23]. Instead, analyses were restricted to overlapping age groups of baby boomers and earlier cohort and baby boomers and later cohort, respectively. Two disjunct subsamples, one comprising members of the earlier and the baby boomer cohort at ages 55-62 (subsample 1) and one containing members of the later and baby boomer cohort at ages 39-46 (subsample 2), were created. All analyses were performed in each of the two subsamples. For an overall characterisation, the subsample-specific cohorts were analysed descriptively regarding sociodemographic-, disorder- and treatment-related characteristics.

Controlling for time variations by including year of data collection as independent variable together with cohort membership in the overlapping age groups would have caused multicollinearity problems [23]. Thus, we applied multilevel regression to account for the nested structure of the data using year of data collection as the level 2 unit. Age at admission was considered by analysing the cohorts in the overlapping age groups. Consequently, the cohort effects are not attributable to age differences between the cohorts. In a sensitivity analysis (SA1), we compared the cohorts across the whole age range at hand. Here, we applied the same multilevel approach, but kept age as a grouped level 1 control variable (overall sample) to explore whether the cohort differences persisted in a larger age range.

Two-level random intercept logistic regression models were applied to test cohort differences using
'AUD' and 'ISUD' as outcome variables. Models with primary diagnoses of opioids, cannabis and stimulants/ cocaine use disorder were run as sensitivity analyses (SA2) to test whether the results differed from the overall model with ISUD as outcome. The number of CUDs was examined by means of two-level random intercept Poisson regression models and results were presented as incidence rate ratios [24].

By calculating the intraclass correlation coefficient in the empty random intercept models for each outcome and conducting a likelihood ratio test, we assessed whether using a random intercept model helped to explain the variance in the outcomes [24,25]. For the outcome 'number of CUDs' in subsample 2, the preanalyses indicated use of a single intercept model. To take time effects into account nevertheless, year of data collection was kept as a second-level unit. Potential covariates were selected based on previous knowledge stemming from the annual report of the German and the Berlin Addiction Care Statistical Service [13,26], and were further investigated in exploratory pre-analyses to examine if they had significant associations with the outcomes. This comprised sex, relationship with a partner, school education, kind of primary diagnosis (not in AUD/ISUD models), number of contacts during treatment and prior utilisation of addiction care (not in AUD/ISUD models). Building on the empty random intercept models, further models were estimated including these preselected covariates as additional level 1 variables (fixed effects). To decide about inclusion, variables were entered one at a time and compared with the empty random intercept model [24].

In all six final models (AUD, ISUD and CUDs for each subsample), besides cohort and sex as predetermined variables, the level of school education and partnership were included as level 1 covariates. Except for ISUD in subsample 1, this applied to the number of contacts during treatment too. In the Poisson models of the number of CUDs, the kind of primary diagnosis and former utilisation of addiction care were added as additional covariates. To investigate the existence of sexspecific cohort effects for AUD and ISUD, a cohort*sex interaction was included in the respective models. Following models were compared [27]: a model with both variables on level 1 and a model containing the interaction term plus cohort and sex. We defined the model with the lower Bayesian information criterion as the better fitting one. For AUD (1) and ISUD (2), it was the model without interaction. The same applied to the sensitivity analyses with cannabis and stimulants/cocaine use disorder. For primary opioids use disorder in subsample 1, it was the model with the interaction term.

All analyses were conducted with Stata/SE 15 (Stata Corp LP; College Station, TX, USA). An alpha level of 0.05 was used for statistical tests. 
Table 1. Cohort characteristics

\begin{tabular}{|c|c|c|c|c|c|c|c|c|}
\hline \multirow[b]{3}{*}{ Characteristics } & \multicolumn{4}{|c|}{$\begin{array}{l}\text { Subsample 1: } \\
\text { Baby boomers vs. earlier cohort }\end{array}$} & \multicolumn{4}{|c|}{$\begin{array}{l}\text { Subsample 2: } \\
\text { Baby boomers vs. later cohort }\end{array}$} \\
\hline & \multicolumn{2}{|c|}{$\begin{array}{l}\text { Baby boomers } \\
\quad(n=4189)\end{array}$} & \multicolumn{2}{|c|}{$\begin{array}{l}\text { Earlier cohort } \\
\quad(n=2335)\end{array}$} & \multicolumn{2}{|c|}{$\begin{array}{l}\text { Baby boomers } \\
\quad(n=7957)\end{array}$} & \multicolumn{2}{|c|}{$\begin{array}{l}\text { Later cohort } \\
(n=7720)\end{array}$} \\
\hline & $\mathrm{n} / \mathrm{M}$ & $\% / \mathrm{SD}$ & $\mathrm{n} / \mathrm{M}$ & $\% / S D$ & $\mathrm{n} / \mathrm{M}$ & $\% / \mathrm{SD}$ & $\mathrm{n} / \mathrm{M}$ & $\% / \mathrm{SD}$ \\
\hline \multicolumn{9}{|l|}{ Sex } \\
\hline Men & 2924 & 69.8 & 1542 & 66.0 & 5620 & 70.6 & 5703 & 73.9 \\
\hline Women & 1265 & 30.2 & 793 & 34.0 & 2337 & 29.4 & 2017 & 26.1 \\
\hline Stable relationship with a partner & 1784 & 42.6 & 1112 & 47.6 & 3198 & 40.2 & 3205 & 41.5 \\
\hline At least middle school education* & 2912 & 69.5 & 1654 & 70.8 & 4898 & 61.6 & 4367 & 56.6 \\
\hline Primary AUD & 3276 & 78.2 & 1994 & 85.4 & 4925 & 61.9 & 3733 & 48.4 \\
\hline Thereof stimulants & 7 & 0.2 & 1 & 0.0 & 71 & 0.9 & 205 & 2.7 \\
\hline Thereof hallucinogens & 1 & 0.0 & 0 & 0.0 & 1 & 0.0 & 1 & 0.0 \\
\hline Thereof volatile solvents & 0 & 0.0 & 0 & 0.0 & 2 & 0.0 & 2 & 0.0 \\
\hline Thereof other psychotropic substances & 3 & 0.1 & 0 & 0.0 & 11 & 0.1 & 13 & 0.2 \\
\hline Primary sedatives/hypnotics use disorder & 67 & 1.6 & 38 & 1.6 & 81 & 1.0 & 69 & 0.9 \\
\hline Primary tobacco use disorder & 68 & 1.6 & 50 & 2.1 & 44 & 0.6 & 49 & 0.6 \\
\hline Primary eating disorder & 2 & 0.1 & 0 & 0.0 & 9 & 0.1 & 4 & 0.1 \\
\hline Primary pathological gambling & 112 & 2.7 & 33 & 1.4 & 172 & 2.2 & 359 & 4.7 \\
\hline Without primary diagnosis, but specified why & 85 & 2.0 & 57 & 2.4 & 209 & 2.6 & 287 & 3.7 \\
\hline Number of CUDs & 1.5 & 1.0 & 1.3 & 0.7 & 1.8 & 1.3 & 1.9 & 1.5 \\
\hline Number of contacts during treatment & 9.4 & 12.9 & 9.5 & 12.6 & 10.2 & 15.1 & 10.2 & 15.6 \\
\hline Utilisation of addiction care ever before & 3163 & 75.7 & 1735 & 74.6 & 5961 & 75.2 & 5603 & 72.9 \\
\hline
\end{tabular}

Note. The primary diagnosis is the addiction-related diagnosis an individual sought help for. *Upper secondary school certificate or higher. AUD, alcohol use disorder; CUD, comorbid substance use disorders; ISUD, illicit substance use disorder.

\section{Results}

\section{Samples' descriptions}

Subsample 1 consisted of 6524 cases, comprising $64.2 \%$ baby boomers. The percentage of women was higher in the earlier cohort (34.0\%) than in the baby boomers (30.2\%). The most frequent primary diagnosis was AUD with $85.4 \%$ in the earlier and $78.2 \%$ in the baby boomer cohort. Members of the earlier cohort were on average diagnosed with 1.3 CUDs $(S D=0.7)$, whereas baby boomers had 1.5 diagnoses $(S D=1.0)$ (Table 1, Figure 1).

In subsample $2,50.8 \%$ of the 15677 cases were baby boomers, and $29.4 \%$ of the baby boomers were female compared with $26.1 \%$ in the later cohort. AUD was the most frequent primary diagnosis presented in $61.9 \%$ of the baby boomers and $48.4 \%$ of the later cohort. Baby boomers were diagnosed with 1.8 CUDs $(S D=1.3)$ and the later cohort had on average 1.9 diagnoses $(S D=1.5)$ (Table 1, Figure 1).

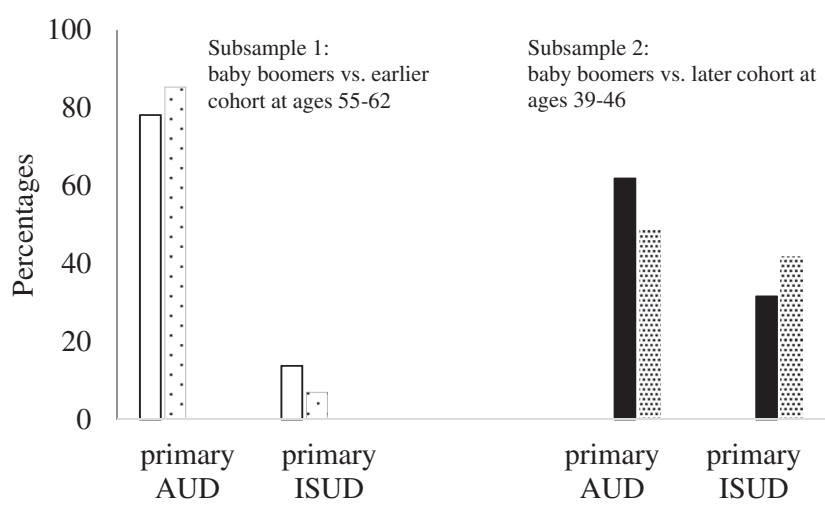

$\square$ baby boomers (55-62 years) • earlier cohort (55-62 years)

- baby boomers (39-46 years) $:$ : later cohort (39-46 years)

Figure 1. Cohort differences. AUD, alcohol use disorder; ISUD, illicit substance use disorder. The primary diagnosis is the addiction-related diagnosis an individual sought help for. 
Table 2. Random intercept logistic regression models of predictors of AUD

\begin{tabular}{|c|c|c|c|c|}
\hline & \multicolumn{2}{|c|}{$\begin{array}{l}\text { Subsample 1: } \\
\text { Baby boomers vs. earlier cohort }\end{array}$} & \multicolumn{2}{|c|}{$\begin{array}{l}\text { Subsample } 2 \text { : } \\
\text { Baby boomers vs. later cohort }\end{array}$} \\
\hline & OR $(95 \% \mathrm{CI})$ & $P$ & OR $(95 \% \mathrm{CI})$ & $P$ \\
\hline \multicolumn{5}{|l|}{ Fixed effects estimates } \\
\hline Intercept & $2.64(2.11,3.32)$ & $<0.001$ & $0.57(0.51,0.63)$ & $<0.001$ \\
\hline \multicolumn{5}{|l|}{ Cohorts } \\
\hline \multicolumn{5}{|l|}{ Sex } \\
\hline Men & 1.00 & & 1.00 & \\
\hline Women & $0.92(0.80,1.05)$ & 0.223 & $1.65(1.53,1.78)$ & $<0.001$ \\
\hline Number of contacts during treatment & $1.01(1.00,1.02)$ & 0.001 & $0.99(0.99,1.00)$ & $<0.001$ \\
\hline \multicolumn{5}{|l|}{ School education } \\
\hline \multicolumn{5}{|l|}{ Random intercept estimates } \\
\hline Estimated residual variance & 0.06 & & 0.01 & \\
\hline Estimated residual intraclass correlations & 0.02 & & 0.00 & \\
\hline Observations & 6524 & & 15677 & \\
\hline $\mathrm{BIC}$ & 6176.85 & & 20358.35 & \\
\hline
\end{tabular}

Note. low $=$ lower secondary school certificate or less; at least middle = upper secondary school certificate or higher; not stable = being single, having a temporary relationship or other forms of relationships (not stable); stable = having a stable relationship with a partner. BIC, Bayesian information criterion; CI, confidence interval; OR, odds ratio.

Two-level random intercept logistic and Poisson regression models

Compared with the earlier cohort, baby boomers showed significantly lower odds for AUD [odds ratio $(\mathrm{OR})=0.79,95 \%$ confidence interval $(\mathrm{CI})=0.66$, 0.95] and, compared with the later cohort, they showed higher odds $(\mathrm{OR}=1.50, \mathrm{CI}=1.37,1.64)$. In subsample 2 across cohorts, women had significantly higher odds for AUD than men $(O R=1.65$, $\mathrm{CI}=1.53,1.78)$. In subsample 1 , there was no significant sex effect for AUD (Table 2).

Compared with the earlier cohort, baby boomers were more likely to present ISUD $(\mathrm{OR}=1.58$, $\mathrm{CI}=1.24,2.03$, see Table 3 ) and compared with the later cohort, baby boomers were less likely to present ISUD $(\mathrm{OR}=0.67, \mathrm{CI}=0.62,0.72)$. In subsample 1 $(\mathrm{OR}=0.63, \mathrm{CI}=0.52,0.76)$ and subsample 2 (OR $=0.58, \mathrm{CI}=0.53,0.63)$, women had lower odds for ISUD than men.

SA2 targeted at distinct illicit substances (opioids, cannabis and stimulants/cocaine as outcomes) confirmed these results (see Tables S1-S3 in the Supporting Information). There were two differences in the distinct substances analysis when compared to the overall ISUD model in subsample 1. First, for primary opioids use disorder there was a sex-specific cohort effect: in women, baby boomers had lower odds than the earlier cohort and in men, the baby boomers had higher odds than the earlier cohort. Second, regarding primary stimulants/cocaine use disorder, the cohort effect was not significant.

Regarding the number of CUDs (Table 4) a significant effect of cohort membership was observed in both subsamples: compared with the earlier cohort, the rate of CUDs was higher in baby boomers (incidence rate ratio $1.10, \mathrm{CI}=1.06,1.15$ ) and, compared with the later cohort the rate was lower for the baby boomer cohort (incidence rate ratio $0.94, \mathrm{CI}=0.91,0.96$ ).

SA1 including the whole age range instead of overlapping age groups confirmed the direction of cohort differences obtained in the main analysis (see Tables S4-S7).

\section{Discussion}

The results indicate that baby boomers in the examined Berlin outpatient addiction care facilities differed from both, an earlier and a later cohort. They were less likely to have AUD compared with the earlier cohort 
Table 3. Random intercept logistic regression models of predictors of ISUD

\begin{tabular}{|c|c|c|c|c|}
\hline & \multicolumn{2}{|c|}{$\begin{array}{l}\text { Subsample 1: } \\
\text { Baby boomers vs. earlier cohort }\end{array}$} & \multicolumn{2}{|c|}{$\begin{array}{l}\text { Subsample } 2 \text { : } \\
\text { Baby boomers vs. later cohort }\end{array}$} \\
\hline \multicolumn{5}{|l|}{ Fixed effects estimates } \\
\hline Intercept & $0.22(0.17,0.29)$ & $<0.001$ & $1.25(1.16,1.34)$ & $<0.001$ \\
\hline Baby boomers & $1.58(1.24,2.03)$ & $<0.001$ & $0.67(0.62,0.72)$ & $<0.001$ \\
\hline \multicolumn{5}{|l|}{ Sex } \\
\hline Men & 1.00 & & 1.00 & \\
\hline Women & $0.63(0.52,0.76)$ & $<0.001$ & $0.58(0.53,0.63)$ & $<0.001$ \\
\hline Number of contacts during treatment & & & $1.02(1.01,1.02)$ & $<0.001$ \\
\hline \multicolumn{5}{|l|}{ School education } \\
\hline \multicolumn{5}{|l|}{ Random intercept estimates } \\
\hline Estimated residual variance & 0.06 & & 0.00 & \\
\hline Estimated residual intraclass correlations & 0.02 & & 0.00 & \\
\hline Observations & 6524 & & 15677 & \\
\hline $\mathrm{BIC}$ & 4318.38 & & 19251.80 & \\
\hline
\end{tabular}

Note. low, lower secondary school certificate or less; at least middle = upper secondary school certificate or higher; not stable = being single, having a temporary relationship or other forms of relationships (not stable); stable = having a stable relationship with a partner. BIC, Bayesian information criterion; CI, confidence interval; OR, odds ratio.

and more likely compared with the later cohort. Moreover, baby boomers were more likely to have ISUD and presented a higher number of CUDs compared with the earlier cohort, but less likely compared with the later cohort. These two-way comparisons indicate that developments set off by the baby boomers regarding the investigated outcomes continue in the later cohort.

Up to now, AUD has been the most frequent primary diagnosis in the German Addiction Care Statistical Service [13]. In line with our hypothesis, seeking help for problems with illicit substances is on the rise in more recent cohorts. These findings are consistent with previous studies in other mainly high-income countries in relation to consumption rates and admissions to addiction care [9-11,21]. This implies that cohort-specific developments in substance use socialisation and addiction care utilisation might be rather general in these countries. Another explanation could be that conditions of poorer health care in the earlier cohort affected life expectancy detrimentally. Therefore, for example, heroin users did not survive long enough to be present in our earlier cohort. Based on the present evidence, outpatient addiction care will have to shift its focus and expertise on illicit substances and the specific health and life situation of this clientele.

No sex-specific cohort effects (interaction of sex*cohort) on AUD and ISUD were found, which suggests that cohort-specific effects are not temporally shifted in women. Here, it should be considered that a narrowing sex gap in consumption and substance use disorder prevalence does not automatically affect addiction care utilisation. Women-specific barriers to addiction care are well known [28,29]. For example, women are more likely to seek help in non-addictionspecific services, as found in a US study [30]. In the case of ISUD, the lack of a sex-specific cohort effect might also result from the relatively small number of women with ISUD, especially in the earlier cohort (subsample with earlier cohort: baby boomers $n=109$; earlier cohort $n=49$ ). Indeed, for opioids use disorder SA1 suggests a sex-specific cohort effect in subsample 1. Female baby boomers had lower odds for opioids use disorder than women in the earlier cohort. The opposite applied to men, which is in line with the overall ISUD model. Hence, further research in samples with a higher share of women is needed to soundly judge whether sex-specific cohort effects remain absent or are only valid for specific substances. 
Table 4. Random intercept Poisson regression models of predictors of the number of CUDs

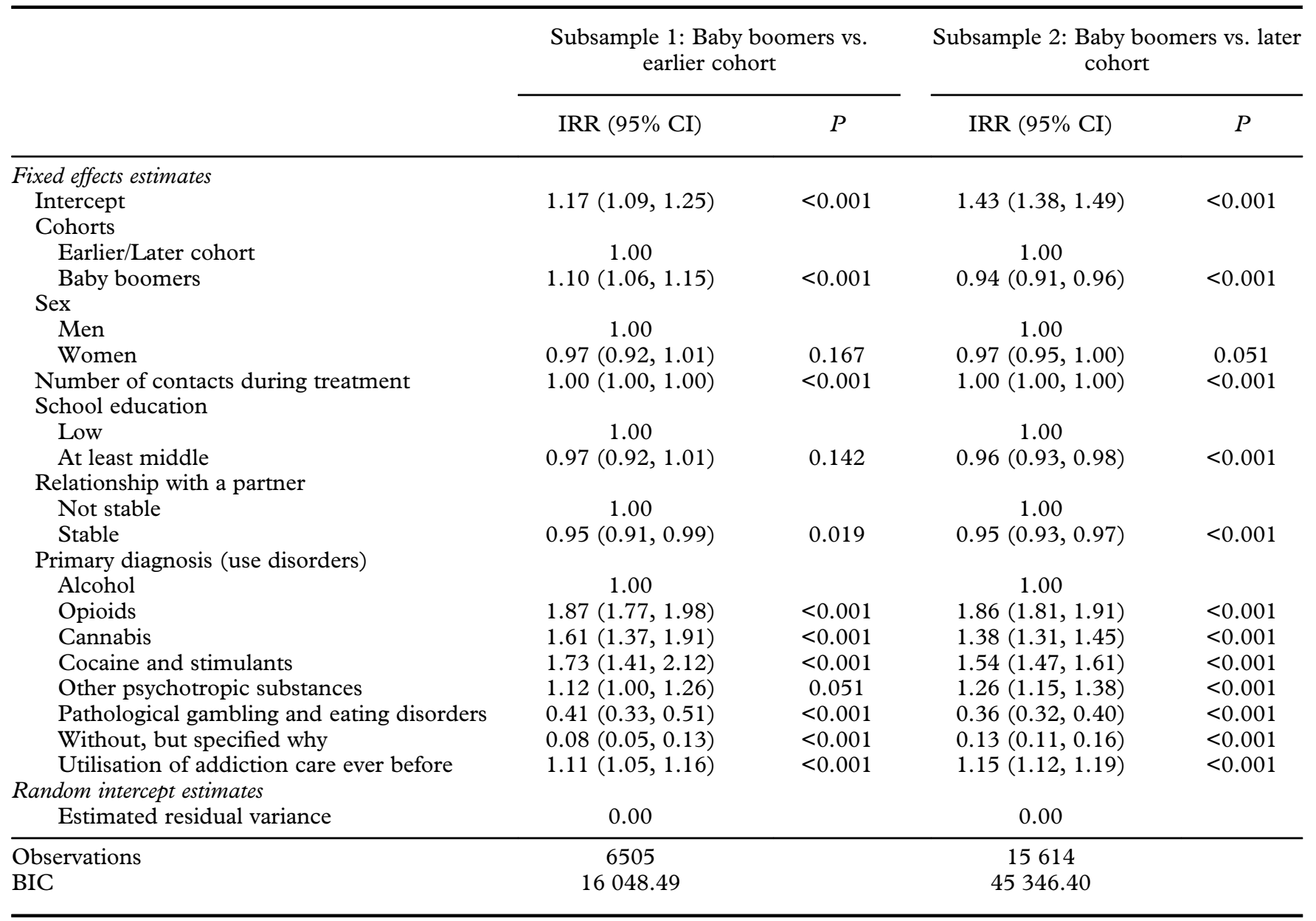

Note . low $=$ lower secondary school certificate or less; at least middle $=$ upper secondary school certificate or higher; not stable $=$ being single, having a temporary relationship or other forms of relationships (not stable); stable = having a stable relationship with a partner; other psychotropic substances = includes sedatives/hypnotics, hallucinogens, tobacco, volatile solvents and other psychotropic substances; $\mathrm{BIC}=$ Bayesian information criterion; $\mathrm{CI}=$ confidence interval; $\mathrm{IRR}=$ incidence rate ratio

In comparison with the earlier cohort, baby boomers showed a higher average number of CUDs and the later cohort presented an even higher rate. This confirms the assumption of later cohorts showing a combination of multiple substance use disorders more often than earlier ones. Individuals with at least two substance-related problems are characterised by higher overall burden $[15,16,18]$ and elevated risks associated with the synergetic effects of polydrug use [15]. This is even more important as the baby boomers get older and prescription drug intake may increase, even more in case of multimorbidity [31]. To handle this issue effectively, outpatient addiction care staff need to build up expertise in case management, communication with primary care physicians and risk minimisation $[16,32,33]$.

The presented results should be interpreted against some study-related caveats. First, generalising the results to Germany as a whole is a sensitive issue. Some differences have been reported between individuals presenting with substance use disorder in outpatient addiction care in Berlin and elsewhere in Germany [34]. For instance, problems with illicit substances as well as multiple substance-related disorders have been found to be more prevalent in Berlin than in Bavaria, a more rural region [34,35]. Despite these regional differences, overall, similar cohort-specific substance use socialisation processes and cohort differences are expected in rural and other urban areas. However, regarding the particular situation of Berlin during the cold war, replication studies in other German regions are needed. Second, there is evidence of an underreporting of co-occurring mental disorders in the documentation of outpatient addiction care services resulting from structural conditions, such as staff not being sufficiently trained in diagnosing co- 
occurring disorders [36]. This may also affect the reporting of comorbid substance use disorders. Based on the assumption that this underreporting occurs at random and is hence not systematically related to cohort and age, the cohort comparisons may be considered valid, even though the true prevalence level of CUDs is assumed to be higher. Third, unknown differences in the assessment of substance-related diagnoses (e.g. unstructured vs. standardised clinical interview) may affect the reliability of the data. As the distribution of the diagnoses is similar in distinct years, this issue is compensated within the sample. Moreover, other outpatient facilities offering, for instance, predominantly psychotherapy should be analysed in future studies.

Despite these drawbacks, the study design offers some important advantages. With its large sample size, the study represents a nearly complete survey of individuals seeking help for addiction-related problems in the Berlin outpatient addiction care system. This comprehensiveness combined with virtually free and unrestricted access to health care in Germany minimises the potential of selection and utilisation bias of point estimates. Second, using complex multilevel modelling and comparing the cohorts in overlapping age groups, it was possible to estimate crude cohort effects that are not masking time changes or age effects. When we analysed the cohorts across all age ranges at hand (SA1) instead of analysing two cohorts in overlapping age groups, cohort differences pointed in the same direction. This suggests that our findings are robust in a wider age range and that the observed differences are not restricted to single age groups. Finally, when analysing illicit substances opposite effects regarding distinct illicit substances might overlie each other. To investigate whether there was a consistent effect in the pooled sample of illicit substances, SA2 disentangled this pooled group into its most frequent underlying single substances (opioids, cannabis, stimulants/cocaine). These analyses unveiled similar patterns as the pooled analyses, suggesting that the observed trends are generalisable to illicit substances as a whole.

\section{Conclusion}

Baby boomers were more likely to seek help because of ISUD and presented a higher number of CUDs than the earlier cohort. The later cohort showed ISUD and CUDs even more often than the baby boomers. This clearly suggests a continuing trend that is anticipated to proceed into later cohorts. In consequence, outpatient addiction care firstly needs to adapt to the gradually changing substance-use characteristics of its clientele including multiple substance use disorders.
Second, with the increased life expectancy and high substance use of the comparatively large cohort of baby boomers, outpatient addiction care needs to prepare for a growing number of older clients who had been underrepresented in addiction care so far. Evidencebased treatment offers for this group are still scarce $[37,38]$ and should be expanded. The growing presence of an older clientele also implies putting more emphasis on harm reduction, tertiary prevention and well-being [32,33] and including geriatric approaches with patient-centred aims such as maintaining independence or symptom management [39].

\section{Acknowledgements}

The authors would like to thank the Berlin Senate Administration for Health, Care and Equality (Berliner Senatsverwaltung für Gesundheit, Pflege und Gleichstellung) for providing data from the Berlin outpatient addiction care system. We would like to thank the staff at the Berlin addiction care facilities who collected the data and are grateful to the participating patients. Data collection in the Berlin addiction care facilities was funded by the Berlin Senate Administration for Health, Care and Equality (grants: 010-2008/I B 34, 002-2010/I B 31, 004-2013/I B $31 \mathrm{a} / \mathrm{b}$ and $08 / 2016$ I B 31). The funder had no role in the study design, analysis, decision to publish or preparation of the manuscript. We thank the Bavarian State Ministry of Health and Care (Bayerisches Staatsministerium für Gesundheit und Pflege) and the Bavarian District Assembly (Bayerischer Bezirketag) for providing the data from the outpatient addiction care sample in Bavaria for comparison purposes.

\section{Conflicts of Interest}

SS, BB-M, LS, N-NS and MW declare that they have no conflict of interests. DP and LK declare having received a grant from Lundbeck $\mathrm{GmbH}$ for a research project on alcohol epidemiology not related to this study.

\section{References}

[1] German Federal Statistical Office. Baby boomers: Germany's largest age group is 50 years old. [Babyboomer: Deutschlands geburtenstärkster Jahrgang wird 50]. Available at: https://www.destatis.de/DE/ ZahlenFakten/ImFokus/Bevoelkerung/BabyboomerGeburten.html (accessed May 2017).

[2] Gilleard C, Higgs P. The third age and the baby boomers. Two approaches to the social structuring of later life. Int J Ageing Later Life 2007;2:13-30.

[3] Menning S, Hoffmann E. The baby boomers-a demographic profile. [Die Babyboomer - ein demografisches Porträt]. Berlin: German Centre 
of Gerontology; 2009. Report No.: 2, 2009. Available at: https://nbnresolving.org/urn:nbn:de:0168-ssoar-370167 (accessed June 2020).

[4] Sudbury-Riley L, Kohlbacher F, Hofmeister A. Baby boomers of different nations. Identifying horizontal international segments based on selfperceived age. Int Mark Rev 2015;32:245-78.

[5] Wang Y-P, Andrade LH. Epidemiology of alcohol and drug use in the elderly. Curr Opin Psychiatry 2013;26:343-8.

[6] Cangelosi PR. Baby boomers: are we ready for their impact on health care? J Psychosoc Nurs Ment Health Serv 2011;49:15-7.

[7] O'Brien RM. Age-period-cohort models: approaches and analyses with aggregate data. Gill J, Heeringa S, Van der Linden W, Long JS, Snijders T, editors. New York: Chapman and Hall/CRC Press; 2015.

[8] Mannheim K. The problem of generations. In: Mannheim K, ed. (translated and ed. P. Kecskemeti)Essays on the Sociology of Knowledge. London: Routledge and Kegan Paul, 1928/1952:276-320.

[9] Duncan DF, Nicholson T, White JB, Bradley DB, Bonaguro J. The baby boomer effect: changing patterns of substance abuse among adults ages 55 and older. J Aging Soc Policy 2010;22:237-48.

[10] Han BH, Sherman S, Mauro PM, Martins SS, Rotenberg J, Palamar JJ. Demographic trends among older cannabis users in the United States, 2006-13. Addiction 2016;112:516-25.

[11] Lay K, King LJ, Rangel J. Changing characteristics of drug use between two older adult cohorts: small sample speculations on baby boomer trends to come. J Soc Work Pract Addict 2008;8:116-26.

[12] Arndt S, Clayton R, Schultz SK. Trends in substance abuse treatment 1998-2008: increasing older adult first-time admissions for illicit drugs. Am J Geriatr Psychiatry 2011;19:704-11.

[13] Dauber H, Specht S, Künzel J, Pfeiffer-Gerschel T, Braun B. Addiction care in Germany 2018: Annual report of the German Addiction Care Statistical Service. [Suchthilfe in Deutschland 2018: Jahresbericht der Deutschen Suchthilfestatistik (DSHS)]. Munich: IFT Institut für Therapieforschung; 2019. Available at: https://www.suchthilfestatistik.de/ fileadmin/user_upload_dshs/Publikationen/Jahresberichte/DSHS Jahresbericht_2018.pdf (accessed June 2020).

[14] Guthrie BJ, Kane Low L. A substance use prevention framework: considering the social context for African American girls. Public Health Nurs 2000; 17:363-73.

[15] Meyerhoff DJ. Functionally relevant brain alterations in polysubstance users: differences to monosubstance users, study challenges, and implications for treatment. In: Watson RR, Zibadi S, eds. Addictive substances and neurological disease: alcohol, tobacco, caffeine, and drugs of abuse in everyday lifestyles. San Diego, CA: Elsevier Academic Press, 2017: 217-37.

[16] Connor JP, Gullo MJ, White A, Kelly AB. Polysubstance use: diagnostic challenges, patterns of use and health. Curr Opin Psychiatry 2014;27: 269-75.

[17] Martinotti G, Carli V, Tedeschi D et al. Mono- and polysubstance dependent subjects differ on social factors, childhood trauma, personality, suicidal behaviour, and comorbid Axis I diagnoses. Addict Behav 2009;34:790-3.

[18] Moss HB, Goldstein RB, Chen CM, Yi H-Y. Patterns of use of other drugs among those with alcohol dependence: associations with drinking behavior and psychopathology. Addict Behav 2015;50:192-8.

[19] Gfroerer JC, Penne M, Pemberton M, Folsom R. Substance abuse treatment need among older adults in 2020: the impact of the aging babyboom cohort. Drug Alcohol Depend 2003;69:127-35.

[20] Han BH, Gfroerer JC, Colliver JD, Penne MA. Substance use disorder among older adults in the United States in 2020. Addiction 2009;104: 88-96.

[21] Wu L-T, Blazer DG. Illicit and nonmedical drug use among older adults: a review. J Aging Health 2011;23:481-504.

[22] German Centre for Addiction Issues (ed.). German documentation manual for addiction care. Definitions and explanations for application. [Deutscher Kerndatensatz zur Dokumentation im Bereich der Suchtkrankenhilfe. Definitionen und Erläuterungen zum Gebrauch]. Hamm; 2010.

[23] Yang Y, Fu WJ, Land KC. A methodological comparison of age-periodcohort models: the intrinsic estimator and conventional generalized linear models. Sociol Methodol 2004;34:75-110.

[24] Hox JJ, Moerbeek M, van de Schoot R. In: Hox JJ, Moerbeek M, van de Schoot R, eds. Multilevel analysis: techniques and applications, 3rd edn. New York: Routledge, 2017.
[25] Rabe-Hesketh S, Skrondal A. Multilevel and longitudinal modeling using Stata, 3rd edn. Lakeway Drive: Stata Press, 2012.

[26] Specht S, Dauber H, Künzel J, Braun B. Addiction Treatment 2017: Annual report on the current situation of addiction treatment in Berlin. [Suchthilfestatistik 2017: Jahresbericht zur aktuellen Situation der Suchthilfe in Berlin]. Munich: IFT Institut für Therapieforschung; 2019. Available at: https://www.suchthilfestatistik.de/fileadmin/user_upload_ dshs/Publikationen/Jahresberichte/Jahresberichte_Laender/ Suchthilfestatistik_Berlin_2017.pdf (accessed June 2020).

[27] Hayes AF. Introduction to mediation, moderation, and conditional process analysis: a regression-based approach. Little TD, editor. New York: The Guilford Press, 2013.

[28] Greenfield SF, Brooks AJ, Gordon SM et al. Substance abuse treatment entry, retention, and outcome in women: a review of the literature. Drug Alcohol Depend 2007;86:1-21.

[29] Rosen CS, Ouimette PC, Sheikh JI, Gregg JA, Moos RH. Physical and sexual abuse history and addiction treatment outcomes. J Stud Alcohol 2002;63:683-7.

[30] Edlund MJ, Booth BM, Han X. Who seeks care where? Utilization of mental health and substance use disorder treatment in two national samples of individuals with alcohol use disorders. J Stud Alcohol Drugs 2012;73:635-46.

[31] Siegmund-Schultze N. Polypharmacotherapy in higher age classes: less medication often is better. [Polypharmakotherapie im Alter: Weniger Medikamente sind oft mehr] Dtsch Arztebl International 2012;109: 418-20.

[32] Bevan G. Problem drug use the public health imperative: what some of the literature says. Subst Abuse Treat Prev Policy 2009;4:21.

[33] European Monitoring Centre for Drugs and Drug Addiction. Treatment and care for older drug users. Luxembourg; 2010. Available at: https:// www.emcdda.europa.eu/system/files/publications/580/EMCDDA_SI10_ Ageing_242756.pdf (accessed June 2020).

[34] Specht S, Künzel J, Braun B. Addiction Treatment 2016. Annual report on the current situation of addiction treatment in Berlin. [Suchthilfestatistik 2016. Jahresbericht zur aktuellen Situation der Suchthilfe in Berlin]. Munich: IFT Institut für Therapieforschung; 2017. Available at: https://www.suchthilfestatistik.de/fileadmin/user_upload dshs/Publikationen/Jahresberichte/Jahresberichte_Laender/ Suchthilfestatistik_Berlin_2016.pdf (accessed May 2020).

[35] Braun B, Specht S, Thaller R, Künzel J. German Addiction Care Statistical Service 2016. Federal state of Bavaria. Tables for outpatien counselling and/or treatment facilities, specialist walk-in clinics and outpatient facilities within institutions. Reference group: admissions and discharges without one-time contacts. [Deutsche Suchthilfestatistik 2016. Bundesland Bayern. Tabellenband für ambulante Beratungs- und/oder Behandlungsstellen, Fachambulanzen und Institutsambulanzen (Typ 3 und 4). Bezugsgruppe: 1 Zugänge Beender ohne Einmalkontakte]. Munich: IFT Institut für Therapieforschung; 2017.

[36] Dauber H, Braun B, Pfeiffer-Gerschel T, Kraus L, Pogarell O. Cooccurring mental disorders in substance abuse treatment: the current health care situation in Germany. Int J Ment Health Addict 2018;16: 66-80.

[37] Andersen K, Behrendt S, Bilberg R et al. Evaluation of adding the community reinforcement approach to motivational enhancement therapy for adults aged 60 years and older with DSM- 5 alcohol use disorder: a randomized controlled trial. Addiction 2020;115:69-81.

[38] Kuerbis A, Sacco P. A review of existing treatments for substance abuse among the elderly and recommendations for future directions. Subst Abuse 2013;7:13-37.

[39] Han BH. Aging, multimorbidity, and substance use disorders: the growing case for integrating the principles of geriatric care and harm reduction. Int J Drug Policy 2018;58:135-6.

\section{Supporting Information}

Additional Supporting Information may be found in the online version of this article at the publisher's website: 
Table S1. Random intercept logistic regression models of predictors of opioids use disorder (with interaction between sex and cohort in subsample 1 and without interaction in subsample 2).

Table S2. Random intercept logistic regression models of predictors of cannabis use disorder.

Table S3. Random intercept logistic regression models of predictors of stimulants and cocaine use disorder.

Table S4. Cohort characteristics in whole-age-range sample.
Table S5. Random intercept logistic regression model of predictors of AUD with interaction between sex and cohort in whole-age-range sample.

Table S6. Random intercept logistic regression model of predictors of ISUD in whole-age-range sample.

Table S7. Random intercept Poisson regression model of predictors of the number of CUDs in whole-agerange sample. 